EDITORIAL

\title{
Impact of Continuing Education on the Quality of Blood Pressure Measurement
}

\author{
Erika Campana ${ }^{1,2}$ and Bruno Daniel Ferrari ${ }^{3}$ (1) \\ Universidade de Nova Iguaçu, 'Rio de Janeiro, RJ - Brazil. \\ Universidade do Estado do Rio de Janeiro, ${ }^{2}$ Rio de Janeiro, RJ - Brazil. \\ Santa Casa de Assis/FEMA SP, '3ão Paulo, SP-Brazil. \\ Editorial referring to the article: Improvement in Semiconductivity on the Measurement of Blood Pressure after an Educational Intervention in \\ Health Professionals
}

Cardiovascular diseases are the leading cause of death worldwide, and a key risk factor for these diseases-hypertension-is unquestionably the most prevalent disease in the population. ${ }^{1}$ Cardiovascular semiology is extremely important in the setting of hypertension (HTN), since the determination of blood pressure values through established indirect measurement techniques plays an essential role in initiating further diagnostic investigation, prompting treatment, and allowing monitoring of patients with HTN. The environment in which measurement is performed; the patient's dietary habits, use of tobacco and alcohol, and engagement in physical activity before measurement; the adequacy of cuff size in relation to the limb; and proper cuff positioning are among the several important aspects which may interfere with measurement reliability. In this context, assessing the technical knowledge of healthcare providers is critical to preventing diagnostic errors. ${ }^{2}$

Differences in magnitude between office BP and mean daytime BP can be attributed both to the environment and to the technical quality of blood pressure measurement by the examiner. Beckett et al. obtained an average of three manual BP readings from 481 hypertensive patients in family practices. The average clinic BP $(151 / 83 \mathrm{mmHg})$ was significantly $(\mathrm{P}<0.001)$ higher than the daytime mean $\mathrm{BP}$ measured by ambulatory blood pressure monitoring (ABPM) (142/80 mmHg). ${ }^{3}$

\section{Keywords}

Hypertension/complications; Cardiovascular Diseases/ mortality; Blood Pressure; Physical Activity; Diet; Quality of Life.
Dawes et al., ${ }^{4}$ in a study with almost 6,000 patients, encouraged family physicians to perform 24-hour ABPM in the largest possible number of patients versus manual blood pressure measurement by the study physician. The average of three readings recorded manually in the office before ABPM was $164 / 96 \mathrm{mmHg}$, compared to a mean daytime ABPM of 149/90 mm Hg. In another series of 309 patients referred for 24-hour ABPM, the last office BP (recorded manually) was $152 / 87 \mathrm{mmHg}$, significantly $(\mathrm{P}<0.001)$ higher than the mean daytime BP recorded by ABPM $(134 / 77 \mathrm{mmHg})$. Data from these studies show a consistent difference of up to $5 \mathrm{mmHg}$ between daytime ABPM and routine office BP. This is a relevant finding, because this difference can be attributed at least partly to measurement errors secondary to poor semiologic technique. ${ }^{5}$

Marchi-Alves et al., ${ }^{6}$ conducted a study of manual blood pressure measurement (with a handheld sphygmomanometer) by nursing providers across five health facilities in the city of Londrina, Paraná. This was a quantitative, observational, cross-sectional study of 80 providers observed from August 2013 to January 2014. The results showed high rates (93.8 to 100\%) of of failure to perform the preparatory stages of blood pressure measurement (i.e., preparing the patient before the actual measurement is taken). Sphygmomanometer calibration was not checked, and there were no different cuff sizes available. The authors concluded that there are significant gaps in the procedures adopted by nursing providers to measure blood pressure, indicating a need for corrective educational measures.

The article published by Bachur CK et al., ${ }^{7}$ in this issue aims to evaluate the theoretical and practical knowledge of blood pressure measurement technique among health professionals before and after an educational

Mailing Address: Erika Campana

Av. Abílio Augusto Távora, 2134. Postal Code: 26275-580, Dom Rodrigo, Nova Iguaçu, RJ - Brazil

E-mail: campanaemg@predialnet.com.br, campanaemg@gmail.com 
intervention. Among the providers evaluated, significant rates of improvement in the blood pressure measurement technique were observed after the educational intervention. These findings reflect that educational

\section{References}

1. Organização Mundial da Saúde. Organização Panamericana da Saúde. 10 principais-causas-de-morte-no-mundo. [Citado em 09 set 2020] Disponível em: phao.org/bra/index/php ¿option=com_ content\&view=article \&id=5638

2. Malachias MVB, Souza WKSB, Plavnik FL, Rodrigues CIS, Brandão AA, Neves MFT, et al. $7^{a}$ Diretriz Brasileira de Hipertensão Arterial. Arq Bras Cardiol 2016; 107(3Supl.3):1-83.

3. Beckett $\mathrm{L}$, Godwin M. The BpTRU automatic blood pressure monitor compared to 24 hour ambulatory blood pressure monitoring in the assessment of blood pressure in patients with hypertension. BMC Cardiovasc Disord. 2005;5(1):18. doi:10.1186/1471-2261-5-18

4. Dawes MG, Coats AJ, Juszczak E. Daytime ambulatory systolic blood pressure is more effective at predicting mortality than clinic blood pressure. Blood Press Monit. 2006;11(3):111-8. doi:10.1097/01.mbp.0000209086.32493.bd interventions and training in proper semiologic technique for blood pressure measurement semiotics are important actions in the Brazilian context, considering their impact on the diagnosis and treatment of HTN in this population.

5. Myers MG, Valdivieso M, Kiss A. Use of automated office blood pressure measurement to reduce the white coat response. J Hypertens. 2009;27(2):280-6.

6. Mouro DL, Godoy de S, Velludo E, Zandomenighi RC, MarchiAlves LM. Práticas adotadas por profissionais de enfermagem para medida indireta e registro da pressão arterial; Practices adopted by nursing professionals for indirect measurement and recording of blood pressure. Ver REME rev min enferm. 2017;21:1-8. doi. org/10.5935/1415-2762.20170005

7. Bachur CK, Candido SS, Silveira GB, Sousa SGO, Neto JH, Veiga EV Improvement in Semiconductivity On The Measurement Of Blood Pressure After An Educational Intervention In Health Professionals. Int J Cardiovasc Sci. 2021; 34(1):1-7. DOI: https://doi.org/10.36660/ ijcs.20190129 